\title{
Teaching Reading and Spelling to Adult Learners: The Multisensory Structured Language Approach
}

\author{
Dr. Shamim Ali \\ Department of English \& Functional Courses, National University of Modern Languages, Pakistan \\ E-mail: dr.shamimali@hotmail.com
}

Received: November 9, 2011

Accepted: February 1, 2012

Published: March 1, 2012

doi:10.5539/elt.v5n3p40

URL: http://dx.doi.org/10.5539/elt.v5n3p40

\begin{abstract}
All over the World most effective methods for teaching reading to beginning-level adults have been applied. My continuing challenge has been to determine how reading acquisition research can be applied to teaching reading to adults. In this article, I describe the techniques I have found most useful; I hope other teachers working with beginning readers will find them helpful. This year my class includes 18 students all were men six men. Their ages range from late $20 \mathrm{~s}$ to late $50 \mathrm{~s}$ and all are employed. Their educational experiences range from completing four to 12 years of school; 12 students have a high secondary school certificate, 03 students have Higher. Secondary School Certificate and 03 students were graduates.
\end{abstract}

Keywords: Adult Learners, Reading Class, Spelling

\section{Introduction}

Over the last 30 years, a significant amount of research has compared the effectiveness of different approaches to teaching beginning reading to Adults. It consistently concludes that approaches that include a systematically organized and explicitly taught program of phonics result in significantly better word recognition, spelling, vocabulary, and comprehension (Chall et al ,1890 ) Reading Skills class depends on the mastery of specific subskills, I find it helpful to teach these explicitly. I organize the class into blocks of time in which, with the help of two volunteers, I directly teach eight components of reading: phonological awareness, word analysis, sight word recognition, spelling, oral reading for accuracy, oral reading for fluency, listening comprehension, and writing. These components embody the skills and strategies that successful readers have mastered, either consciously or unconsciously. My lesson plan also includes an intensive writing component. For this reason, I directly teach the structure of the English language using a phonics-based approach. I draw from a number of phonics-based reading programs, including the Wilson Reading System, the Orton-Gillingham System, and the Lindamood-Phoneme Sequencing Program). The Wilson Reading System is a multisensory, phonics-based program developed specifically for adults, who have difficulty with decoding (reading) and encoding (spelling). It is a complete curriculum that has 12 steps, beginning with phoneme segmentation. Its main goal is to teach students language and word structure through a carefully planned program. The program was developed in Massachusetts in the 1980s by Barbara A. Wilson, based on knowledge gained from working with adults with dyslexia using Orton-Gillingham methodology at Massachusetts General Hospital's Language Disorders Unit, and with students in an after-school reading clinic founded with her husband, Ed Wilson. The Wilson Reading System, published in 1989, is now commonly used in various settings throughout the United States and several other countries Wilson Reading System is useful for one-to-one tutoring, in small groups, and in reading classes. There are two different vocabulary levels: The first one is the "Level A" which is appropriate for elementary, English-as-a-Second-Language and older students with inadequate vocabularies; and the second one is the "Level B" is appropriate for students who are beyond elementary grades with more complex vocabularies.

The program incorporates five elements for teaching at-risk populations:

- $\quad$ phonemic awareness

- direct instruction of word analysis, prosody and comprehension

- coordination of reading and spelling instruction

- intensive, cumulative instruction

- $\quad$ teaching for mastery 
The second programme which I applied is The Orton-Gillingham program. It is a phonics-based program similar to the Wilson Reading System but designed for dyslexic children. Students learn about syllables much later in the program. I find particularly helpful the Orton-Gillingham technique for learning phonetically irregular sight words. Samuel Torrey Orton (1879-1948), a neuropsychiatrist and pathologist at Columbia University, brought together neuroscientific information and principles of remediation. As early as the $1920 \mathrm{~s}$, he had extensively studied children with the kind of language processing difficulties now commonly associated with dyslexia and had formulated a set of teaching principles and practices for such children. Anna Gillingham (1878-1963) was an educator and psychologist at Teachers College, Columbia University. Working with Dr. Orton, she trained teachers and compiled and published instructional materials. Gillingham combined Orton's teaching methods with her analysis of the structure of the English/American language and with Bessie Stillman, she wrote what has become the Orton-Gillingham manual: Remedial Training for Children with Specific Disability in Reading, Spelling and Penmanship. First published in 1935/6, this work is updated and republished regularly. This programme has five features such as:

1. Language-based: The Orton-Gillingham approach is based on a technique of studying and teaching language, understanding the nature of human language, the mechanisms involved in learning, and the language-learning processes in individuals.

2. Multisensory: Orton-Gillingham teaching sessions are action-oriented and involve constant interaction between the teacher and the student and the simultaneous use of multiple sensory input channels reinforcing each other for optimal learning. Using auditory, visual, and kinesthetic elements, all language skills taught are reinforced by having the student listen, speak, read and write. For example, a dyslexic learner is taught to see the letter A, say its name and sound and write it in the air - all at the same time. The approach requires intense instruction with ample practice. The use of multiple input channels is thought to enhance memory storage and retrieval by providing multiple "triggers" for memory.

3. Structured, Sequential, and Cumulative: The Orton-Gillingham teacher introduces the elements of the language systematically. Sound-symbol associations along with linguistic rules and generalizations are introduced in a linguistically logical, understandable order. Students begin by reading and writing sounds in isolation. Then they blend the sounds into syllables and words. Students learn the elements of language - consonants, vowels, digraphs, blends, and diphthongs - in an orderly fashion. They then proceed to advanced structural elements such as syllable types, roots, and affixes. As students learn new material, they continue to review old material to the level of automaticity. The teacher addresses vocabulary, sentence structure, composition, and reading comprehension in a similar structured, sequential, and cumulative manner.

4. Cognitive: Students learn about the history of the English language and study the many generalizations and rules that govern its structure. They also learn how best they can learn and apply the language knowledge necessary for achieving reading and writing competencies.

5. Flexible: Orton-Gillingham teaching is diagnostic and prescriptive in nature. Teachers try to ensure the learner is not simply recognising a pattern and applying it without understanding. When confusion of a previously taught rule is discovered, it is re-taught from the beginning.

The third approach which I have mentioned above is The LiPS Program. It is useful for helping students acquire an awareness of individual sounds in words. This ability, referred to as phonemic awareness, is a prerequisite for reading and spelling. A primary cause of decoding and spelling problems is weak phonemic awareness, the ability to think about sound (phonemes) within words. A significant number of students- even those who have received phonics instruction- only perceive words as a whole, and can't tell what the component sounds are and their order. Thus, they can't figure words out, and must memorize or guess from context. LiPS (formerly known as Auditory Discrimination in Depth) provides theory and methodology for successfully developing phonemic awareness. The program begins with discovering how speech sounds are articulated, and extends into multisyllable and contextual reading and spelling. LiPS uses a multisensory approach for increasing knowledge of letter symbols and their accompanying sounds. In particular, LiPS teaches children to identify sounds from the feedback from the positions of their lips, tongue, and jaw to help them discriminate sounds from each other. Hands-on instruction with use of manipulatives is incorporated to assist children in combining sounds into words for reading and spelling

\section{Literature Review}

Phonological awareness, which involves the ability to differentiate and manipulate the individual sounds, or phonemes, in words, is the strongest predictor of future reading success for children (Adams, 1995). No research exists that describes the affects of phonological awareness on reading for adults. However, I have found that teaching phonological awareness to my certificate-reading adults significantly improves their reading accuracy and spelling, 
especially for reading and spelling words with blends. Three phonological tasks that I use with my students, in order of difficulty, are auditory blending, auditory segmenting, and phonemic manipulation. Auditory blending involves asking students to blend words that the teacher presents in segmented form. For example, I say "/s/-/k/-/i/-/r/-/t/" and the students responds with "/splash/". Auditory segmenting is exactly the opposite. I present the word "/sprint/" and the student must segment the word into its individual sounds "/s/-/k/-/i/-/t//" Phonemic manipulation, which is the strongest predictor of reading acquisition, is also the most difficult. The student must recognize that individual phonemes may be added, deleted, or moved around in words. The following exchange is an example of a phonemic manipulation task. I ask the student to repeat a word such as "sand". Then I ask the student to say the word again, changing one of the phonemes. For example, "Say it again without the "///". The student responds with "/sink/". While phonological awareness does not include the student's ability to associate sounds with letter symbols, and tasks are presented orally, the research concludes that the most effective way to promote phonemic awareness is in conjunction with the teaching of sound-to-symbol relationships (Torgesen, 1998).

[Insert Table 1 here]

\subsection{Word Analysis with Syllable Pattern}

Word analysis, or phonics, involves teaching the alphabetic principle: learning that the graphic letter symbols in our alphabet correspond to speech sounds, and that these symbols and sounds can be blended together to form real words. Word analysis strategies enable students to "sound out" words they are unable to recognize by sight. Explicit, direct instruction in phonics has been proven to support beginning reading and spelling growth better than opportunistic attention to phonics while reading, especially for students with suspected reading disabilities (Blackman et al., 1984; Chall, 1967, 1983). Beginning readers should be encouraged to decode unfamiliar words as opposed to reading them by sight, because it requires attention to every letter in sequence from left to right. This helps to fix the letter patterns in the word in a reader's memory. Eventually, these patterns are recognized instantaneously and words appear to be recognized holistically (Ehri, 1992; Adams, 1990).

I use the Wilson Reading System to teach phonics because the six syllable types are introduced early on. This enables even beginning-level adults to read words that are part of their oral vocabulary and overall cognitive abilities. After learning the closed syllable rule, for example, students are able to read three-syllable words such as "Wisconsin," "fantastic," and "Atlantic." Reading multisyllabic words provides my students, who have acquired a history of reading failure, with an unexpected sense of accomplishment and opens possibilities for them. Recogn-izing syllable types is important because the syllable pattern determines the sound of the vowel and how the word must be pronounced.

[Insert Table 2 here]

I have found that the Wilson Reading System Sound Tapping technique is a particularly effective way to teach decoding. In this technique, each sound in a word is represented by one tap. Students tap the first sound with their index finger and thumb, the second sound with their middle finger and thumb, the third sound with their ring finger and thumb, etc. If the student runs out of fingers, he or she returns to the index finger. Digraphs - two letters that make one sound (/sh/, /ch/, /th/, /ck/,/ph/) - are represented with one tap. Example: bed $=3$ sounds, 3 taps; shed $=3$ sounds, 3 taps; stint $=5$ sounds, 5 taps. This technique helps students to hear all the sounds in a word.

\subsection{Memorization through Visualization "Sight Word" Recognition}

I have experienced some success in teaching sight words using the Visual-Auditory-Kinesthetic-Tactile (V-A-K-T) method that is part of the Orton- Gillingham program The VAKT method, which emphasizes memorization through visualization, involves asking the student to say the name of each letter in a word and to trace each letter with his or her finger in the air before covering the word and attempting to spell it on paper. The VAKT method may be used to help students with both the reading and spelling of phonetically irregular words. Since many of the words that appear most frequently in print are phonetically irregular, even beginning readers must learn to recognize some words by sight. Students with reading disabilities have typically relied almost entirely on their ability to memorize words. In most cases, however, their strategies for remembering the way words look in print have proved ineffective. To avoid unnecessary frustration, it is best to tell beginning readers which words they should decode and which words they must recognize by sight.Effective technique for the spelling of phonetically regular words is the LiPS technique. This involves asking students to put down a poker chip for each sound they hear. After identifying the correct number of sounds in the word, students locate the vowel sound and place a different-colored chip over the chip that represents the vowel sound. Only after they have identified the sounds and isolated the vowel sound are students asked to select the letter symbols that represent the sounds in the word. Nonsense words require the student to use word attack strategies as opposed to sight recognition Spelling is an effective way to reinforce both word analysis skills and automatic word recognition. Research consistently indicates that fluent, skilled readers (both children and adults) make use of spelling patterns when they read and, conversely, reading itself reinforces a knowledge of spelling patterns (Adams, 1995). 
Spelling for practicing word analysis skills and spelling for promoting word recognition (usually of phonetically irregular words), however, involve different tasks and call for different teaching techniques. The VAKT method, described earlier, is a process for teaching learners how to spell phonetically irregular words. When dictating phonetically regular words, include only those words that include letter sounds and spelling rules that have been taught directly.

\subsection{Penciling Method for Oral Reading}

Oral reading builds accuracy and fluency, both of which contribute to improved reading comprehension. It is also the most practical way for me to monitor a student's progress. It gives a student an opportunity to practice applying word attack and word recognition skills in context. Because reading for fluency and reading for accuracy involve different objectives and require different materials, I find it useful to teach and evaluate them as two separate activities .Oral reading for accuracy gives students an opportunity to use the word analysis skills they have been taught directly, so I choose reading selections from controlled texts. The book I have selected for this purpose is Follow Through .During accuracy reading, the emphasis is on using word analysis students to read smoothly and with expression. When asking my students to do fluency reading, I do not interrupt the flow of the reading to discuss the content of the text or to analyze a particular spelling pattern. If the student makes a mistake, I provide the word. Because it is difficult to find materials that are easy enough for a beginning reader to read fluently, I often address fluency in the context of rereading material students have first read for accuracy. The Wilson Reading System describes a technique for promoting fluency called penciling that I have found particularly useful. I encourage the student to read more than one word in a breath by scooping a series of words together with a pencil. First, I model how the sentence should be read. For example: "The man with the hat is big." Eventually, students are able to pencil the sentences for themselves but, at the beginning, I scoop words into phrases for them.

\subsection{Using Photographs for Comprehension}

I teach higher-level comprehension skills using materials other than those the students can read themselves. In my class, critical thinking usually takes place in the context of a classroom debate. Topics I have found particularly conducive to a heated discussion Using photographs is also effective in building higher-level comprehension skills. I ask questions such as "What do you think the people in the photograph are feeling?" "How can you tell?" or "What do you think may have happened to make them feel that way?" Open-ended questions encourage students to make inferences, draw conclusions, and express opinions.

\section{Conclusion}

The challenge of teaching reading to beginning-level adults can be daunting. In my opinion, however, teaching at this level is also the most rewarding. It is extremely moving to witness an adult who, after years of struggling with the sounds of individual letters, is able to read a letter from a family member or a note that his or her child brings home from school. Progress can be excruciatingly slow for adult readers ,but at same time it is very challenging.

\section{References}

Adams, M. J. (1990). Beginning to Read: Thinking and Learning about Print. Cambridge, MA: MIT Press.

Adams, M. J. (1995). Resolving the "great debate". American Educator, 19(2)

Blackman, J., Bruck, M., Herbert, M., \& Seidenberg, M. (1984). Acquisition and use of spelling-sound correspondences in reading. Journal of Experimental Child Psychology, 38, 114-133. http://dx.doi.org/10.1016/0022-0965(84)90022-5

Chall, J. S. (1967). Learning to Read: The Great Debate. New York: McGraw-Hill.

Chall, J. S. (1983). Stages of Reading Development. New York: McGraw-Hill.

Curtis, M. E. (1980). Development of components of reading skill. Journal of Educational Psychology, 72, 656-669. http://dx.doi.org/10.1037/0022-0663.72.5.656

Ehri, L. C. (1992). Reconceptualizing the development of sight word reading and its relationship to encoding. In P. Gough, L. Ehri, \& R. Treiman (eds.), Reading Acquisition (pp. 107-144). Hillsdale, NJ: Erlbaum Associates.

Snow, C., \& Strucker, J. (2000). Lessons from preventing reading difficulties in young children for adult learning and literacy. In J. Comings, B. Garner, \& C. Smith (eds.), Annual Review for Adult Learning and Literacy, Vol. 1, 25-69. San Francisco: Jossey-Bass, Inc.

Stanovich, K. E. (1986). Matthew effects in reading: Some consequences of individual differences in acquisition of literacy. Reading Research Quarterly, 21, 360-407. http://dx.doi.org/10.1598/RRQ.21.4.1

Torgesen, J. (1998). Catch them before they fall; Identification and assessment to prevent reading failure in young 
children. American Educator, 32-39

Wilson Reading Systems. (2002). Wilson language training overview. [Online] Available: www.wilsonlanguage.com

Author: Dr Shamim Ali, Ph.D., is a Professor in the Department of English, Faculty of Functional Courses at National University of Modern Languages, Islamabad, Pakistan. She earned her doctoral Degree in English Linguistics. She is the member of Reading committee and the interdisciplinary Ph.D.program in Second Language Acquisition and Teaching at the National University of Modern Languages Islamabad Pakistan. Her areas of interest include computer-assisted instruction for the teaching of foreign/ second languages, and materials design and development. She is the author of numerous articles on Second language learning, Reading Skills, Teachers' Education, TEFL Methodology, Assessment \&Evaluation, Discourse Analysis, computer-assisted language learning (CALL), Bilingualism as well as three books on Adult language reading.

Table 1. Typical Lesson Plan for an-Hour Class

\begin{tabular}{|lc|}
\hline Typical Lesson Plan for an-Hour Class & \\
\hline Component & Time (min) \\
\hline Word Analysis/ Spelling & 10 \\
Word Recognition "Sight Words" & 10 \\
Oral Reading & 10 \\
Comprehension & 10 \\
Writing & 10 \\
\hline
\end{tabular}


Table 2. Syllable Types

\begin{tabular}{|c|c|}
\hline \multicolumn{2}{|l|}{ Syllable Types } \\
\hline SYLLABLE TYPE & DESCRIPTION \\
\hline Closed Syllable (vc/cv) & $\begin{array}{l}\text { - one vowel per syllable } \\
\text { - ends with one or more consonants } \\
\text { - the vowel has a short sound } \\
\text { example: pit, bath, splash, mitten }\end{array}$ \\
\hline $\begin{array}{l}\text { Vowel-Consonant-e } \\
\text { Syllable (vce) }\end{array}$ & $\begin{array}{l}\text { - one vowel, then a consonant, then an e } \\
\text { - the first vowel has a long sound } \\
\text { - the e is silent } \\
\text { example: hope, mine, bedtime }\end{array}$ \\
\hline Open Syllable (v/cv), (vc/v) & $\begin{array}{l}\text { - one vowel } \\
\text { - ends with the vowel } \\
\text { - vowel has a long sound } \\
\text { example: me, so, flu, why }\end{array}$ \\
\hline R-Controlled Syllable & $\begin{array}{l}\text { - one vowel, followed by an r } \\
\text { - vowel sound is neither short or long } \\
\text { - vowel sound is controlled by the r } \\
\text { - /ar/ as in "car," /or/ as in "Ford," / er/, /ir/, /ur/ all sound alike as in "her," "bird," "church" }\end{array}$ \\
\hline The Consonant-LE Syllable & $\begin{array}{l}\text { - has three letters: a consonant, an "l," and an "e" } \\
\text { - the e is silent } \\
\text { - the consonant and the "l" are blended together } \\
\text { example: little, grumble, table }\end{array}$ \\
\hline The Double-Vowel Syllable & $\begin{array}{l}\text { - two vowels side-by-side making one sound } \\
\text { - usually the first vowel is long, and the second is silent } \\
\text { example: maid, may, leaf, seen, pie, goat }\end{array}$ \\
\hline
\end{tabular}

